But it is not our purpose to enter on considerations of this nature, which have indeed only too frequently forced themselves on the attention of Judges and Lawyers. We shall, in conclusion, only refer to the opinion of so strong an opposer of progress as Lord EIdon. "Improvements in the law," he remarked in a well known case, "or some things which have been considered as improvements, have been lately proposed; and if among these things called improvement, this donatio mortis causa, was struck out of our law altogether, it would be quite as well. ${ }^{1}$

\title{
FORENSIC MEDICINE.
}

OBSERVATIONS ON THE TESTS FOR ARSENIC.

Iv the Comptes Rendus of the 15th of last January, may be found an account of some curious researches on the time required to eliminate certain poisons from the blood. These experiments were conducted by M. Orfila, a nephew of the great Toxicologist, and were designed to solve a problem of equal interest to the physician and the medical jurist.

Orfila found that, when corrosive sublimate has been given for a number of days, so as to allow of its diffusion through the system, it usually disappears from the organs in eight or ten days, and is never to be found after the eighteenth day. In like manner, lead and copper are proved to remain in the body, for eight months after the experimenters ceased to give them by the mouth.

It is easy to illustrate the practical value of these researches by imagining cases, where, a person having died under circumstances leading to a suspicion of poisoning, and a poison being found in minute amount in his tissues, it is also shown that he had previously taken the same poison, in medicinal doses, for a length of time. The medical evidence in such a case would materially depend upon a knowledge of how long the poison, whatsoever its character, 
would be likely to remain in the body. Nor are these cases wholly theoretical. We will state briefly two of those recorded by Orfila. A man underwent a course of treatment by corrosive sublimate, which is a mercurial compound; four months after he died, and, on examination, mercury was found in his system. According to $0 \mathrm{r}-$ fila's experiments, corrosive sublimate could never be detected after the eighteenth day. It was, therefore, very improbable that the mercury found in this case was a remnant of that medicinally given months before.

Again:-a lead manufacturer died two months after giving up his business. Lead was found in his organs. Was it due to his previous trade, ór to poison more recently given? We are atrare that lead may remain in the body for many months, and the decision as to poisoning must therefore depend less on the expert's evidence than on collateral testimony.

On the other hand, should death from mercurial poison be delayed beyond the fifteenth day, there will be but. little chance of detection.

It is much to be regretted that these researches were not extended to Arsenic. Of this poison, considered in this relation, we know but very little. Persons poisoned by arsenic have died from its effects two years after the dose was given. The longest time between the taking of the poison and consequent death, where also arsenic was found on examination, is that of Reg. v. Part. An arsenical plaster was applied to a cancer by a quack, who removed it when the symptoms became serious. The roman died in two weeks after its removal. Yet Dr. Brett detected arsenic in the liver, the substance of the stomach, and the spleen. The quantity detected was less than one quarter of a grain. The prisoner was acquitted.' This case is valuable as showing us that arsenic may be discovered in the organs when the death has been delayed until two weeks after its administration. Any further information in this direction must be obtained by direct experiment. The last mentioned case illustrates also the importance of a clear knowledge 
of the tests for arsenic, and of their relative degrees of delicacy. With a poison like this, which, in a dose of one ounce will not injure one person, whilst in a dose of three grains it will kill another; it becomes essential to the purposes of correct evidence that our tests should be adequate for the detection of quantities almost microscopic. Very recently considerable advances have been made in regard to a correct appreciation of the relative value of the various methods resorted to for the discovery of arsenic. A brief review of the subject may therefore present certain points of interest.

In some of the older processes the odor of arsenic was dwelt upon as a test of some value, but as this odor belongs to it only when passing from one state to another, as when it is burned, we must regard it as of little value.

The liquid tests for arsenic are three in number.

1. If ammoniacle nitrate of silver be added to a solution of arsenious acid, (i. e. white arsenic,) an insoluble yellow precipitate will fall-this is the arsenite of silver.

2. If the amonio-sulphate of copper be added to an arsenious solution, a soluble sulphate of ammonia is formed, while an insoluble green arsenite of copper falls.

3. When a current of sulphuretted hydrogen gas is conducted through an arsenious acid solution, slightly acidulated, the arsenic of the arsenious acid unites with the sulphur of the gas to make a yellow insoluble sulphuret of arsenic. The first of these tests is the most delicate. All three are subject to fallacies, because arsenic is to be sought most commonly in solutions containing many ingredients. It is enough to add that all fallacies will be avoided if the expert has collected the precipitates, and tested them by the reduction process. This consists in heating the precipitate with a flux, in a glass tube. If arsenic be present, the well known arsenical ring will occur. We can now re-dissolve this isolated arsenic, and repeat any, or all of the tests, without dread of fallacy.

The arsenical ring, formed during the process of reduction, is so peculiar, that according to Christison, "no substance in nature which can be sublimed by a like process at all resembles it." One 
substance, and one only, bears it to any great likeness, and that is the ring caused by the sublimation of cinnabar, (i. e. red sulphuret of mercury.) The rings of this substance were first made some years ago, during experiments upon a well known case of poisoning which occurred at Doylestown. ${ }^{1}$ Their perfect resemblance to arsenic misled several chemists of experience. The liquid tests would of course reveal their true nature. Examination of the arsenical ring should always be undertaken, whether the arsenic be obtained by the liquid tests or by any other means.

There remains to us two tests.

4. Marsh's test. This depends upon the fact, that arsenic and hydrogen form together an inflamable gas, and that, if we cast a jet of the burning gas upon a white surface, arsenic will be deposited, forming a peculiar stain.

Lassaigne collects the arsenic by passing the gas into nitrate of silver, whereby arsenite of silver is formed, and may be collected and re-tested. If the stain be not adhesive, it is only a little oily matter. If phosphuretted hydrogen be present there will be a stain, and an odour much like that of arsenic. If antimony be present there will also be a stain. Secondary testing will be decisive as to the nature of the stain. Properly managed, Marsh's test . detects the one fifty-thousanth of a grain of arsenic.

Very recently this subject of the tests for arsenic has been re-examined by several observers. ${ }^{2}$ They all agree as to the superior value of the test which we have yet to describe. In certainty, delicacy, and freedom from fallacy, it undoubtedly surpasses the process of Marsh.

5. This is denominated Reinsch's test. The arsenic in solution -is to be acidulated with one-sixth part of hydrochloric acid and boiled. If a small piece of copper foil, or wire, be now allowed to remain in the liquid, it will soon acquire a dark gray tinge, owing to a deposit of arsenic upon the copper. This process, if repeated often enough, will remove all the arsenic from the solution, and

1 Med. \& Phys. Journal, 1832, p. 121, et. seq.

2 Amongst others, Campbell Morfit, and Prof. J. C. Booth, of Philadelphis. 